\title{
Violentar o Corpo da Imagem: uma estratégia para representar e resistir à barbárie
}

CAMILA MONTEIRO SCHENKEL

Camila Monteiro Schenkel é professora e pesquisadora do Instituto de Artes da Universidade Federal do Rio Grande do Sul. Possui doutorado no Programa de Pós-Graduação em Artes Visuais da UFRGS com estágio na Universidade de Bolonha. Em 2017, foi bolsista CAPES PNPD junto ao mesmo programa, investigando continuidades e descontinuidades entre a imagem digital e processos fotográficos que a antecederam. Integra o Grupo de Pesquisa do CNPq "Deslocamentos da fotografia na arte".

AFILIAÇÃO: Universidade Federal do Rio Grande do Sul , Porto Alegre, RS, Brasil 
- RESUMO

O presente artigo busca refletir sobre a representação e a problematização da violência em trabalhos de arte contemporânea, tomando como fio condutor "Postais para Charles Lynch", do coletivo Garapa. Na obra, o grupo provoca falhas e ruídos em frames extraídos de vídeos de linchamentos para velar sua reprodução explícita e, simultaneamente, violar o corpo da imagem. Por meio da análise desse trabalho, da realização de entrevistas com os artistas e do diálogo com reflexões desenvolvidas por Joan Fontcuberta, Hito Steyerl e Jacques Rancière, procura-se investigar a presença e a circulação de imagens de suplício público do corpo no contexto da cultura digital, assim como o potencial da arte para ressignificá-las.

\section{PALAVRAS-CHAVE}

Arte Contemporânea, imagem digital, apropriação, violência.

\section{ABSTRACT}

This article reflects on the representation of the violated body in contemporary art through the analysis of "Postais para Charles Lynch", by Garapa collective. In this work, the group provokes form and color distortions in frames extracted from videos of lynchings as a strategy to cover their explicit representation and, simoutaneously, violate the body of the image. Considering interviews with the artists, the analysis of the work and texts of Joan Fontcuberta, Hito Steyerl and Jacques Rancière, this article investigates the presence and circulation of images of public body agressions in the digital culture context, as well as the potential offered by art to reframe them.

\section{KEYWORDS}

Contemporary art, digital image, appropriation, violence. 


\title{
Introdução
}

No início de fevereiro de 2014, a imprensa noticiava o caso de um adolescente que teria praticado assaltos pelo bairro do Flamengo, no Rio de Janeiro. A imagem que circulava pelas redes sociais de seu corpo negro nu, com sinais evidentes de espancamento, trouxe mais uma vez à tona os fantasmas da escravidão que, diariamente, evitamos encarar. Segundo a vítima, ele e mais três amigos que conseguiram escapar foram perseguidos por um grupo de cerca de trinta homens que atuavam na região, conhecidos como "justiceiros de moto". Depois de ser agredido com capacetes, socos e pontapés, sem que ninguém na rua fizesse nada para impedir, o jovem de quinze anos foi despido e preso ao poste por uma correia de bicicleta (OLIVEIRA, 2014).

Outro caso emblemático do período ocorreu em São Paulo, no Guarujá, em maio do mesmo ano, quando a dona de casa Fabiane Maria de Jesus morreu após ser amarrada e espancada por moradores do bairro Morrinhos. Fabiane foi associada a um retrato falado que havia sido divulgado pelo site de denúncias populares Guarujá Alerta, junto com boatos sobre uma suposta sequestradora atuante na região, que estaria utilizando crianças em rituais de magia negra.

Impactada por essa série de eventos e pelo modo como eles foram cobertos pela mídia, a Garapa, ${ }^{1}$ coletivo de fotógrafos fundado em São Paulo em 2008, desenvolveu um projeto de investigação voltado para o modo como imagens de violência são disseminadas pela internet. Além da preocupação com a banalização desse tipo de barbárie, outro disparador do trabalho foi o inflamado comentário da colunista Rachel Sheherazade sobre o episódio no bairro do Flamengo, transmitido pelo SBT no dia 4 de fevereiro: ${ }^{2}$

\begin{abstract}
O marginalzinho amarrado ao poste era tão inocente que, ao invés de prestar queixa contra seus agressores, preferiu fugir antes que ele mesmo acabasse preso. É que a ficha do sujeito está mais suja do que pau de galinheiro. No país que ostenta incríveis 26 assassinatos a cada 100 mil habitantes, que arquiva mais de $80 \%$ de inquéritos de homicídio e sofre de violência endêmica, a atitude dos vingadores é até compreensível. O Estado é omisso, a polícia é desmoralizada, a Justiça é falha. $O$ que resta ao cidadão de bem que, ainda por cima, foi desarmado? Se defender, é claro. O contra-ataque aos bandidos é o que chamo de legítima defesa coletiva de uma sociedade sem Estado contra um estado de violência sem limite. E, aos defensores dos Direitos Humanos, que se apiedaram do marginalzinho preso ao poste, eu lanço uma campanha: faça um favor ao Brasil, adote um bandido (Apud GARAPA, 2015, p. 22).
\end{abstract}

\footnotetext{
${ }^{1}$ Coletivo fundado em São Paulo em 2008 por Leo Caobelli (Pelotas, R.S., 1980), Paulo Fehlauer (Mal. Candido Rondon, P.R., 1982) e Rodrigo Marcondes (São Paulo, S.P., 1979), três fotógrafos que decidiram trocar a redação de um grande jornal por um projeto que permitisse um maior investimento de tempo, energia e reflexão nas imagens que produziam. Seu trabalho artístico propõe tensionar as fronteiras entre documentário e artes visuais por meio de narrativas que integram múltiplos formatos e linguagens. Atuam também como uma produtora audiovisual, produzindo conteúdo para TV, web e cinema. No final de 2015, com a saída de Caobelli, a Garapa transformou-se em um duo. Como garapa (caldo extraído da cana-de-açúcar a partir do qual se produz a cachaça) é um substantivo feminino, o coletivo adota o artigo feminino ao se referir ao seu nome. Adotei o mesmo critério ao longo do texto.

2 Trechos do discurso de Sheherezade e sua imagem, inclusive, acabaram incluídos no trabalho final.
} 
A proposta do coletivo, intitulada "Postais para Charles Lynch", foi contemplada com a Bolsa de Fotografia ZUM 2014, do Instituto Moreira Salles. Após um longo processo de compilação e análise de vídeos de linchamentos que circulam na internet, a estratégia encontrada pelo grupo foi procurar pensar esse tipo de imagem dentro de uma perspectiva histórica mais ampla e, ao mesmo tempo, explorar a maleabilidade das imagens digitais e a velocidade com que elas circulam nas redes. O projeto foi finalizado em outubro de 2015 , tendo como resultado um livro de artista, com tiragem de duas cópias, que foi exposto no Estúdio Madalena e na exposição "Fotos contam fatos", na Galeria Vermelho, em 2015 e, mais recentemente, na mostra "Corpo a corpo", realizada no IMS Rio. O material pode ser visualizado por um público mais amplo em um vídeo disponível no site do coletivo, que mostra o livro sendo folheado, onde também se pode acessar um ensaio que comenta as reflexões geradas pelo projeto. ${ }^{3} \mathrm{~A}$ partir da análise dessa obra, o presente artigo procura desenvolver uma reflexão sobre o modo como as imagens de violência que circulam pelos meios digitais podem ser trabalhadas pela arte contemporânea.

\section{Charles Lynch e a persistência das imagens da barbárie}

Com a popularização de telefones celulares que permitem a um número cada vez maior de usuários fotografar, filmar e se conectar à internet a qualquer momento, imagens de linchamentos tonaram-se cada vez mais fáceis de produzir e compartilhar. Ainda que sejam proibidas pelas políticas de conteúdo de sites como YouTube, elas reaparecem em outro ponto da rede tão logo são banidas de determinado canal. A persistência desse tipo de material no tecido social pode parecer, à primeira vista, um sintoma das tensões da esfera pública contemporânea. No entanto, como nos lembra o trabalho desenvolvido pela Garapa, ela conta com um histórico mais longo. Assinalar com precisão as origens do fascínio por imagens de espetáculos públicos de suplício do corpo, sejam eles perpetrados pelo Estado ou por indivíduos comuns, seria evidentemente difícil. A opção do coletivo, em vez disso, foi investigar o surgimento do termo linchamento. É justamente essa gênese que dá nome ao trabalho.

Charles Lynch, a figura para quem são dedicados os postais do título, foi um fazendeiro do estado da Virgínia, nos Estados Unidos, que, durante o período da guerra de independência, instalou uma corte extrajudicial em seu condado para julgar e punir colonos que apoiassem a coroa britânica. A partir da Guerra da Secessão, o termo lynching passou a ser usado para fazer referência a execuções públicas com participação popular, que tinham como principais vítimas homens negros do sul do país. No final do século XIX, essas execuções tornaram-se assunto de registro fotográfico e até mesmo de comércio e troca de cartões postais, fato que levou, em 1908, os correios a determinarem a proibição de seu envio (GARAPA, 2015).

Uma amostra abrangente dessas fotografias e postais de linchamento foi reunida pelo colecionador James Allen e posteriormente publicada no livro "Without Sanctuary" (2000). Entre outras informações, o livro de Allen traz o depoimento de Leon F. Litwack sobre o linchamento de Thomas Brooks, ocorrido em Tennessee,

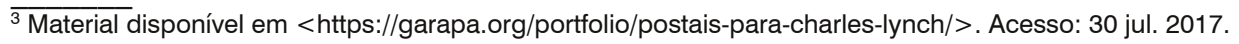


1915, que nos ajuda a compreender o papel da fotografia nessas manifestações de violência popular:

Centenas de Kodaks clicavam no local do linchamento durante toda a manhã. Pessoas vinham de muito longe em automóveis e carruagens para ver o cadáver pendurado na ponta de uma corda... Fotógrafos de cartões postais instalaram na ponte uma máquina de impressão portátil, e colhiam uma safra na venda de cartões com a fotografia do negro linchado [...] Em várias escolas rurais a rotina do dia foi adiada para que meninos e meninas pudessem ver o homem linchado (Apud GARAPA, 2015, p. 32). ${ }^{4}$

Ao resgatar a história do termo, o grupo relaciona os linchamentos ocorridos nos Estados Unidos entre os séculos XIX e XX e o comércio fotográfico gerado por esses acontecimentos com os linchamentos registrados recentemente no Brasil e o modo como eles são divulgados na internet. Para o coletivo, tanto os postais do início do século quanto os vídeos que hoje são veiculados no YouTube se baseiam em uma linguagem visual usualmente associada a uma função documental (a fotografia ou o vídeo de celular), envolvem uma forma de compartilhamento popular em sua época (o correio ou a internet) e são, ainda, atravessados por um viés moralizante - "como se, por meio da transmissão, buscassem legitimar as ações representadas" (GARAPA, 2015, p. 44).

Essas aproximações são desenvolvidas pelo coletivo no ensaio "Postais para Charles Lynch (notas de um percurso sobre a barbárie)", que comenta as motivações e as reflexões surgidas ao longo do trabalho. Nesse material, chamam a atenção as seguintes perguntas, que parecem indicar o cerne de sua investigação: "De que maneira a superexposição às imagens da violência nos afeta em relação aos eventos registrados? Esse afetar acontece no sentido da ação ou da imobilidade, da memória ou do apagamento?" (GARAPA, 2015, p. 6) Trata-se de dúvidas que se impõem a todos que produzem e consomem imagens, sintetizando um dilema histórico de fotógrafos que se dedicam a revelar os aspectos mais trágicos e sombrios da existência humana. Afinal de contas, com quais propósitos esses registros são produzidos e divulgados? E quais os efeitos de sua circulação?

O ensaio tem como base pesquisas do Núcleo de Estudos da Violência da USP e textos de Michel Foucault, Susan Sontag e Frank Möller, entre outras referências. Ao longo do texto, a questão dos linchamentos é abordada a partir de referências históricas a espetáculos públicos de suplício do corpo, considerações sobre a posição do espectador diante de imagens de violência e dados sobre linchamentos no Brasil contemporâneo.

\section{Abrindo a Caixa de Pandora: o que fazer com esse tipo de imagem?}

A primeira fase do trabalho envolveu a busca e a compilação de vídeos de linchamento que se encontravam em circulação no período. A quantidade de regis-

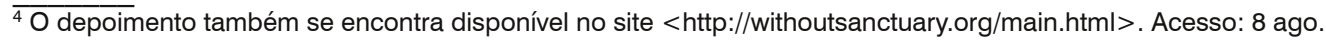
2017.

ouvirouver Uberlândia v. 15 n. 1 p. 158-170 jan.|jun. 2019
} 
tros encontrada, por si só, já constitui um dado significativo: conforme levantamento do grupo, em julho de 2015 a pesquisa pelos termos "linchamento" e "linchado" no YouTube rendia aproximadamente 31.300 resultados (GARAPA, 2015, p. 50). Inicialmente, o material foi apenas armazenado, sendo que os vídeos muitas vezes nem eram assistidos por completo. Essa foi a etapa mais longa do projeto, que se estendeu por cerca de cinco meses, e foi realizada de modo individual por cada um dos integrantes do grupo. A parte de processamento do material coletado, que incluía tanto a decupagem e a transcrição de alguns vídeos quanto a seleção e a manipulação de imagens, foi realizada no período final da bolsa e durou em torno de um mês.

Diante do desafio de lidar com essas imagens que alimentam o ódio e a violência coletiva, o grupo optou por selecionar frames dos vídeos, transformando-os em imagens fixas, para depois realizar interferências em sua estrutura, de maneira a gerar distorções de forma e de cor. O processo escolhido para essas intervenções foi a manipulação direta do código desses arquivos, provocando dessa forma falhas e ruídos em sua aparência. A operação remete ao glitch, termo de origem alemã que designa um erro em uma máquina, aparelho ou sistema, utilizado para denominar falhas visuais que ocorrem em imagens eletrônicas e alteram sua aparência de maneira aleatória. Seja ele intencional ou acidental, o glitch, para o coletivo, "tem a capacidade de desnudar as estruturas (eletrônicas, econômicas, políticas) que organizam e se impõem ao mundo" (GARAPA, 2015, p. 60).

Para corromper os arquivos dos frames selecionados, a Garapa utilizou trechos de comentários postados no YouTube por algumas das pessoas que visualizaram os vídeos. Fragmentos desses textos, como os descritos abaixo, foram inseridos entre o código das imagens por meio de três softwares diferentes, provocando o surgimento de linhas, faixas e cortes.

- Si todos que fosse pego tivesse um tratozinho desses difícil seria encontrar ladrão

- Sou pai de família e torço por uma sociedade melhor. Alguns talvez não entenda mas as vezes é preciso derramar um pouco de sangue pra ter um pouco de paz. Devemos nos unir e se preocuparmos com nossos filhos que poderão ser vítimas fatais de monstro como esses quem perdeu seu filho na mão de um ladrão sabe o que estou dizendo.

- É engraçado o povo brasileiro só é macho quando tem um monte de gente junto... isso é tentativa de homicídio ou seja todos são bandidos.

- Lindo ver ladrão sendo linxado. Pena que não morreu. ${ }^{5}$

\footnotetext{
$\overline{5}$ Uma versão digital do trabalho pode ser consultada em:

$<$ https://issuu.com/fehlauer/docs/postais_para_charles_lynch>. Acesso: 30 jul. 2017.
} 


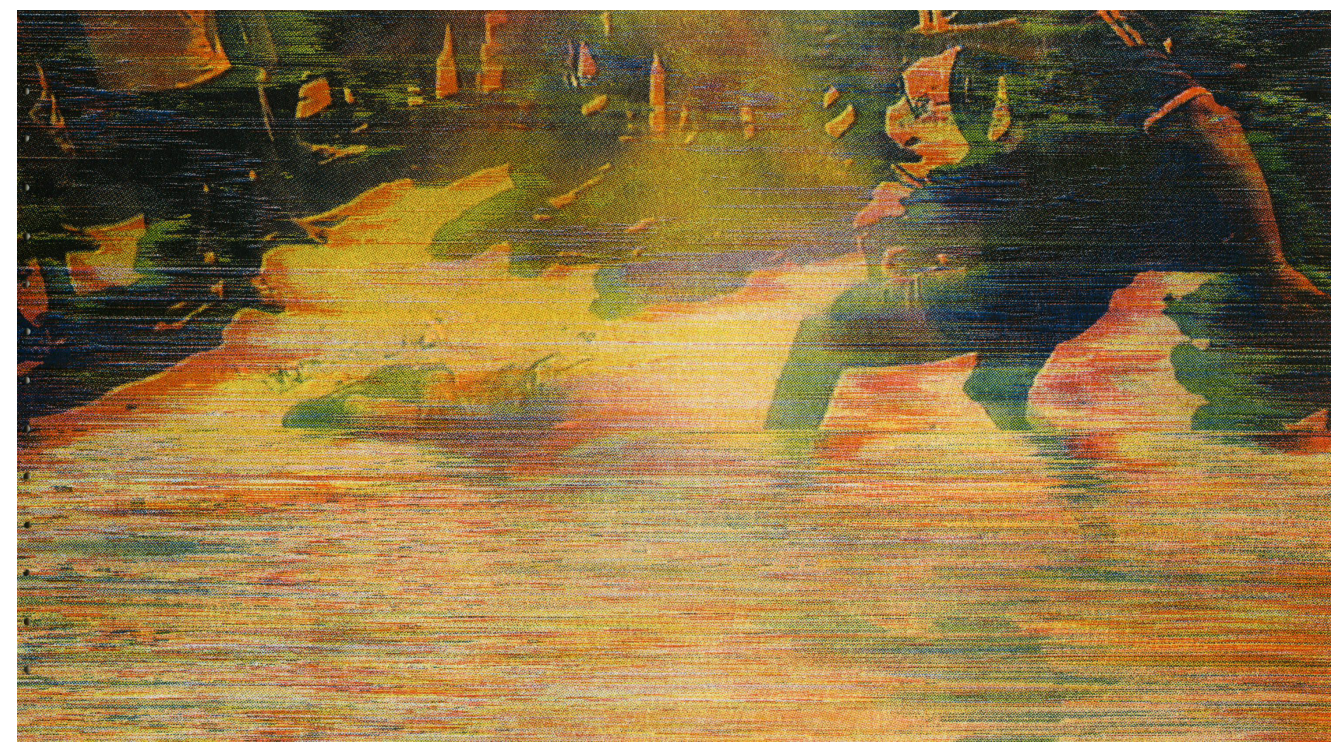

Figura 1. Garapa, Postais para Charles Lynch, 2015 (detalhe). Livro, 16cm x 27cm, 64 p. Fonte: arquivo dos artistas.

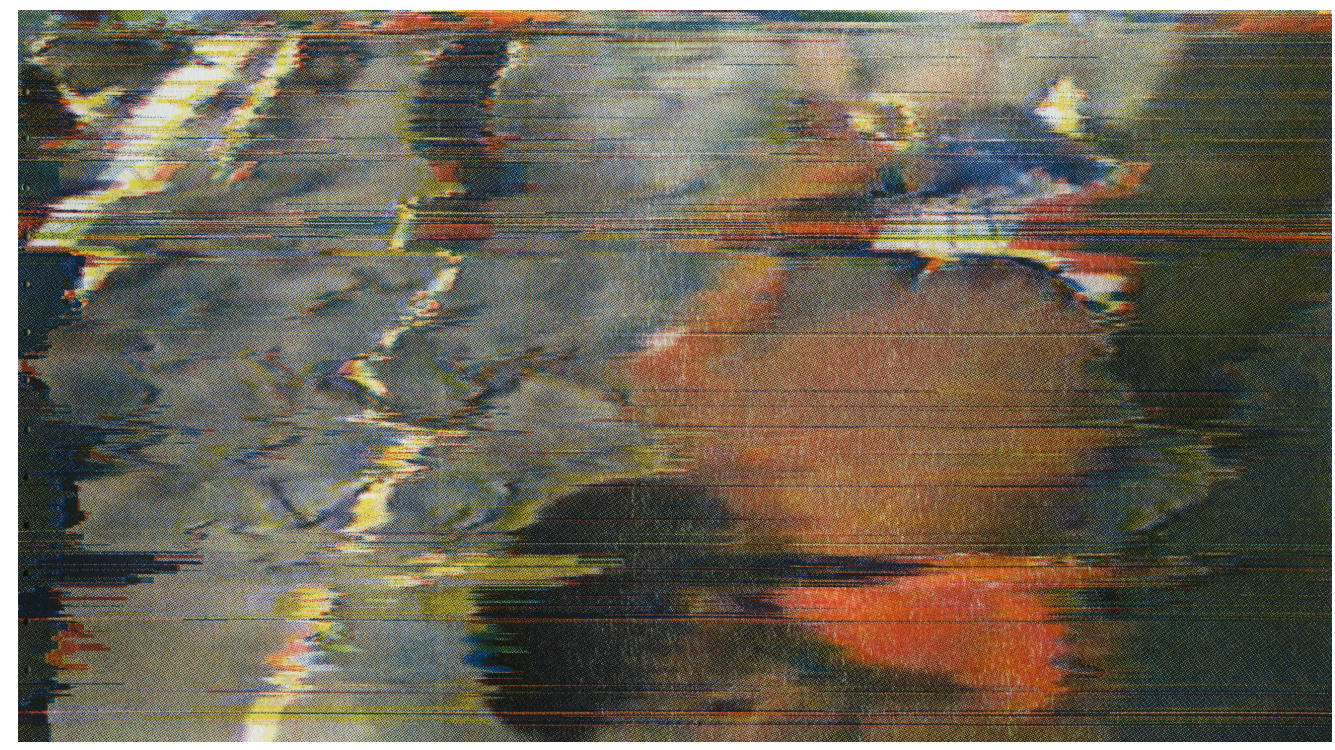

Figura 2. Garapa, Postais para Charles Lynch, 2015 (detalhe). Livro, 16cm x 27cm, 64 p. Fonte: arquivo dos artistas.

Diferente do glitch tradicional, no qual os ruídos são gerados ao acaso, por problemas no funcionamento da câmera ou do computador, o glitch utilizado pela Garapa foi se tornando cada vez mais consciente, na medida em que os integrantes observavam os efeitos de diferentes tipos de interferência nos arquivos das imagens. Conforme o software, o tipo de arquivo utilizado (TIF ou jpg, por exemplo) e a posição na qual o texto era inserido no código, o resultado visual variava (Figura 1 e 2). 
As operações plásticas realizadas pelo grupo funcionam como uma forma de diferenciação estética das imagens de linchamentos que circularam pela mídia e pelas redes sociais, assemelhando-se a veladuras que vão pouco a pouco encobrindo suas qualidades descritivas. Tais interferências podem ser vistas, ainda, como uma necessidade do coletivo de ocultar seu conteúdo de violência explícita a fim de conseguir trabalhar com elas e depois compartilhá-las. Ao mesmo tempo, a manipulação dessas imagens confere um efeito pictórico ao trabalho, concedendoIhes uma aparência mais abstrata e até mesmo atraente. A elaboração de um ensaio teórico que problematiza a questão da representação da violência com base em argumentos históricos, sociológicos, filosóficos e artísticos poderia ser entendida, dentro desse contexto, como uma defesa antecipada dos autores a possíveis acusações de estetização da violência.

Entre as trinta e seis imagens impressas no livro, no entanto, algumas não sofreram interferências. No caso de duas delas, o motivo foi sua resolução, bastante baixa, que já oferecia algum tipo de ruído e dificuldade ao olhar. No caso de outras duas - a fotografia do adolescente carioca acorrentado ao poste e o retrato falado que provocou, por engano, a morte da dona de casa Fabiane Maria de Jesus (Figura 3) - o motivo talvez tenha sido o caráter emblemático que essas imagens adquiriram, não apenas para o grupo, mas para o próprio debate sobre a violência coletiva no país. No trabalho final, os frames manipulados foram associados a páginas que simulam seus códigos corrompidos, que permitem que se leia, entre letras e números, trechos dos comentários de pessoas que assistiram aos vídeos - esses sim, apresentados sem nenhum filtro que atenue seu discurso de ódio (Figura 4).

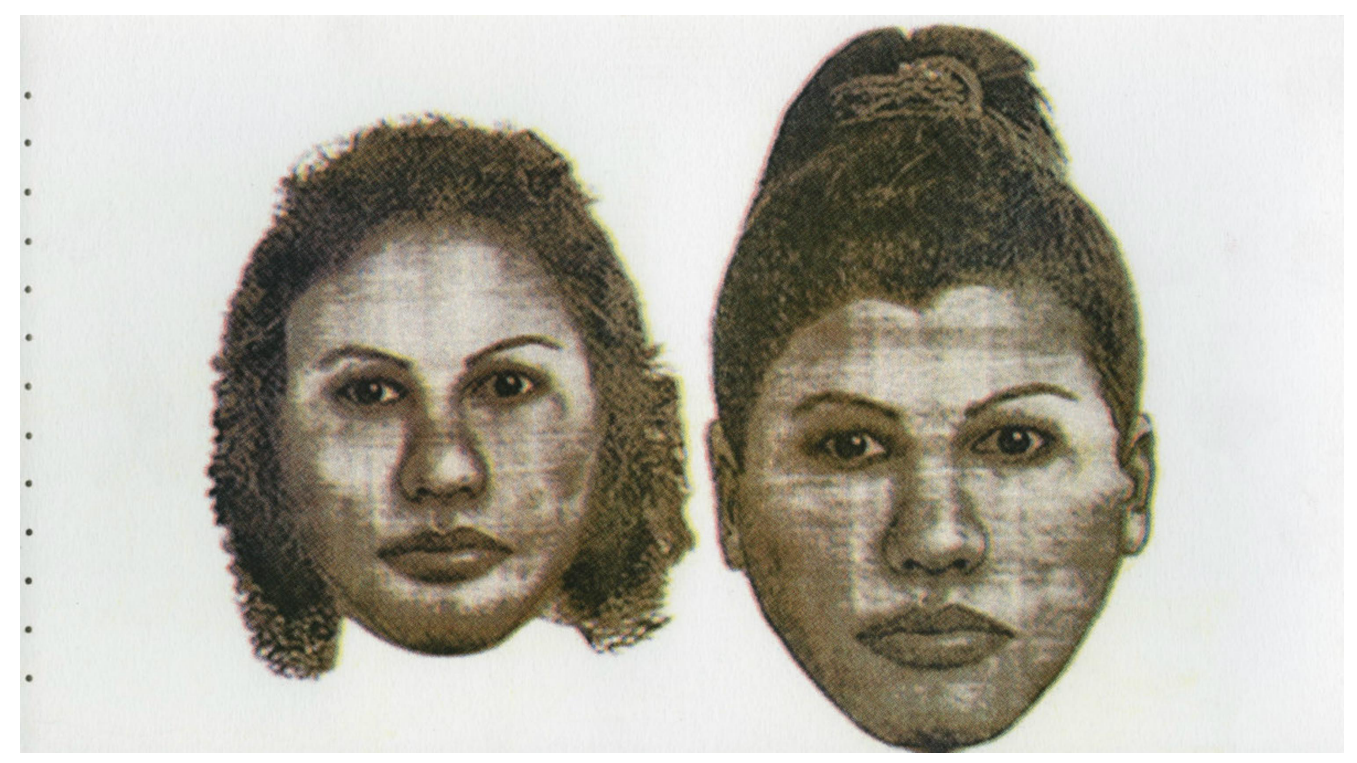

Figura 3. Garapa, Postais para Charles Lynch, 2015 (detalhe). Livro, $16 \mathrm{~cm} \times 27 \mathrm{~cm}, 64$ p. Fonte: arquivo dos artistas. 


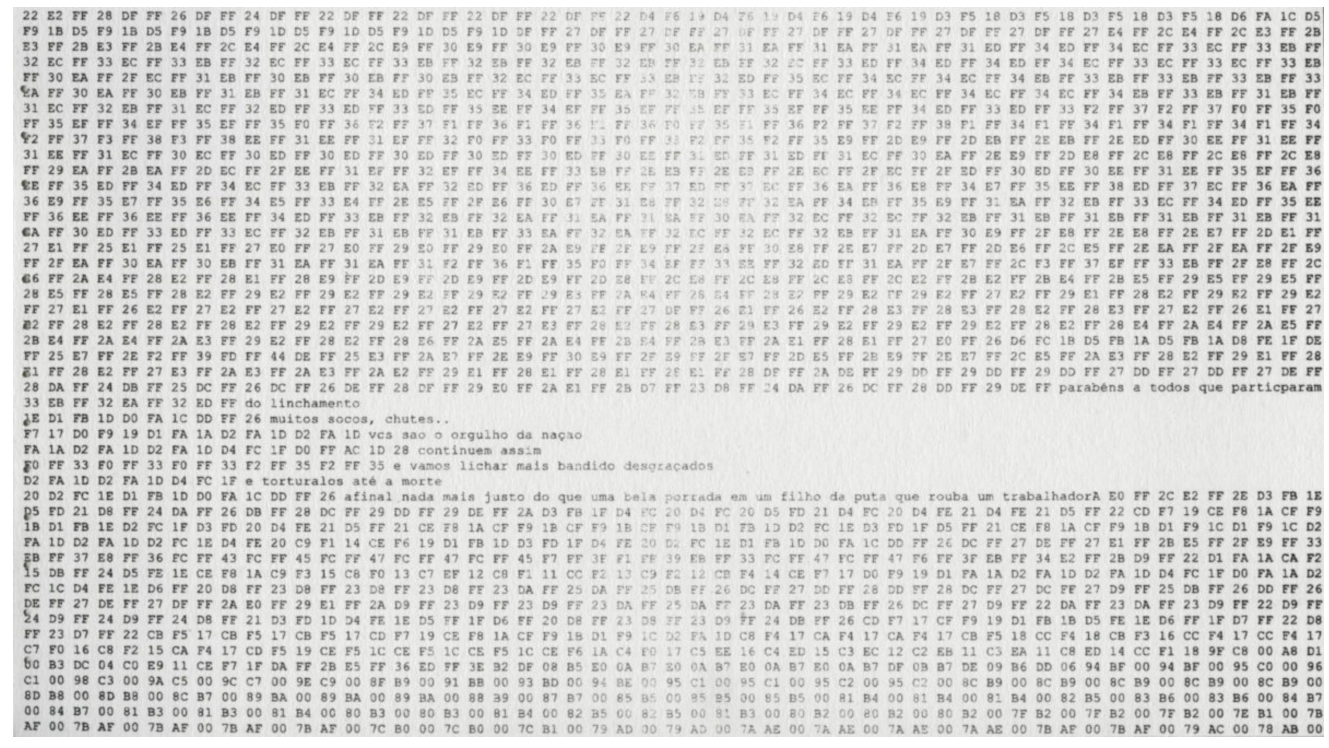

Figura 4. Garapa, Postais para Charles Lynch, 2015 (detalhe). Livro, 16cm x 27cm, 64 p. Fonte: arquivo dos artistas.

A técnica de impressão utilizada para a elaboração do livro, a risografia, reforça o aspecto pictórico do material, uma vez que a programação da máquina acentua a distorção e a saturação de determinadas cores. Além dessas imagens, o trabalho traz um texto em forma de roteiro, elaborado a partir de personagens e comportamentos recorrentes observados nos vídeos de linchamento, e uma fita LTO (Linear Tape-Open) na qual estão armazenados os vídeos compilados pelo grupo. Trata-se de uma mídia mais difícil de acessar, porém mais durável que discos rígidos externos. Os integrantes do coletivo associam essa fita à ideia de caixa-preta, uma vez que ela armazena as informações recolhidas ao longo de todo o desenvolvimento do trabalho. Tal imagem é reforçada pela capa de aço que envolve o livro. ${ }^{6}$

\section{Apropriação e manipulação de imagens no contexto digital}

"Postais para Charles Lynch" é o primeiro projeto para o qual os integrantes da Garapa não realizaram nenhuma captação direta de fotografias ou de vídeos, trabalhando apenas com apropriação. Seu ponto de partida são imagens que já se encontram em circulação, produzidas para fins de documentação e comunicação, sem objetivos artísticos. Ao mesmo tempo, é um trabalho que joga com a estrutura das imagens contemporâneas, investigando as relações entre a linguagem codificada da fotografia digital e a simulação icônica produzida cada vez que um desses arquivos é acessado.

O processo de apropriação e interferência em imagens digitais que caracteriza a elaboração de "Postais para Charles Lynch" revela outro elemento conceitual importante para o projeto: a ideia de pós-fotografia, especialmente do modo como ela é apresentada por Joan Fontcuberta. Essa referência aparece tanto no projeto

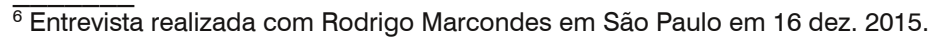


submetido ao Instituto Moreira Salles quanto em declarações posteriores do coletivo. No artigo "Por um manifesto pós-fotográfico", publicado originalmente em 2011, o fotógrafo catalão reflete sobre as mudanças proporcionadas pela popularização da fotografia digital, que provocaram um abalo irreversível no cânone do fotojornalismo. Em um mundo marcado pela "poluição icônica", no qual a velocidade prevalece sobre o instante decisivo, as fotografias, anteriormente objetos de recordação, "se convertem em puros gestos de comunicação, cuja dimensão pandêmica obedece a um amplo espectro de motivações" (FONTCUBERTA, 2014, p. 130). As imagens, agora transformadas em pixels e adaptadas a nossa vida online, encontram-se disponíveis a todos. Em meio a essa abundância de fotografias, cabe ao artista, em vez da função de produzi-las, a tarefa de prescrever-lhes novos significados: "faz sentido esforçar-me para tomar uma foto adicional? [...] Vale a pena enriquecer a contaminação gráfica reinante?", questiona o autor (FONTCUBERTA, 2014, p. 124).

A incorporação da estética da falha e a precariedade visual dos vídeos que são o ponto de partida de "Postais para Charles Lynch", no entanto, poderiam ser relacionadas a outro texto em estilo de manifesto que também problematiza a imagem contemporânea: "In Defense of the Poor Image", de Hito Steyerl. No ensaio publicado originalmente no jornal "E-flux" em novembro de 2009, a artista alemã analisa os efeitos causados pela transferência das imagens do contexto fixo e regrado de arquivos e cinemas, por exemplo, às incertezas do cenário digital. Na medida em que perdem substância e ganham velocidade, a acessibilidade e o alcance de fotografias e vídeos se tornam mais relevantes do que características como qualidade formal, definição e nitidez.

A imagem pobre é uma cópia em movimento. Sua qualidade é ruim, sua resolução abaixo do padrão. Na medida em que se acelera, se deteriora. É um fantasma de imagem, uma pré-visualização, uma miniatura, uma ideia errante, uma imagem itinerante distribuída de graça, espremida por meio de conexões digitais lentas, comprimida, reproduzida, rasgada, remixada, e também copiada e colada em outros canais de distribuição. (STEYERL, 2012, p. 32) (tradução minha). ${ }^{7}$

Entre as consequências dessas transformações, Steyerl aponta que, por um lado, boa parte das imagens que circulam hoje na internet operam contra o fetiche da alta resolução, mas, por outro, acabam perfeitamente integradas a um capitalismo de informação. Livres e precárias, rápidas e onipresentes, essas imagens parecem responder às condições de nosso tempo, assim como a fotografia de base química cristalizou as aspirações da modernidade.

As imagens contemporâneas encontram-se migrando constantemente entre arquivos, pastas, computadores e celulares. A cada vez que são abertas e salvas novamente, são de alguma forma alteradas, afastando-se de suas origens e sua finalidade inicial. No caso específico de "Postais para Charles Lynch", a Garapa, ao

\footnotetext{
${ }^{7}$ No original: The poor image is a copy in motion. Its quality is bad, its resolution substandard. As it accelerates, it deteriorates. It is a ghost of an image, a preview, a thumbnail, an errant idea, an itinerant image distributed for free, squeezed through slow digital connections, compressed, reproduced, ripped, remixed, as well as copied and pasted into other channels of distribution (STEYERL, 2012, p. 32).
} 
selecionar, captar, manipular e imprimir trechos de vídeos em circulação possibilita que esse material seja visto de outras formas, ainda que no contexto restrito dos festivais de fotografia e das exposições de arte. O coletivo confere, assim, um novo tempo a essas imagens, abrindo-as para novos significados e outros tipos de funções.

\section{E por que insistir em olhar para essas imagens?}

Tendo destacado algumas das questões de técnica e de linguagem que permeiam "Postais para Charles Lynch", gostaria de voltar ao ponto de origem do trabalho: a representação da violência e o problema que a produção e a manipulação de registros reais da barbárie apresentam para artistas e fotógrafos que se propõem a lidar com esse tipo de material. Como nos lembra Susan Sontag (2003) em sua célebre reflexão sobre as fotografias de guerra, choque e vergonha se misturam quando olhamos para uma representação de um horror real. Mas qual seriam os efeitos de olhar para imagens de sofrimento extremos, e qual a linha que separa a sensibilização do voyeurismo? Como a autora aponta, no caso de imagens de atrocidade, espera-se, usualmente, "o peso do testemunho sem a mancha da artisticidade, que é associada à falsidade ou ao mero artifício" (SONTAG, 2003, p. 26) (tradução minha) ${ }^{8}$. Diante desse recato socialmente exigido, "talvez as únicas pessoas com direito a olhar para imagens de sofrimento dessa ordem extrema sejam aquelas que poderiam fazer algo para aliviá-lo [...] ou aquelas que podem aprender algo a partir dele" (SONTAG, 2003, p. 42) (tradução minha) ${ }^{9}$.

Poucos anos depois da publicação do ensaio de Sontag, o filósofo Jacques Rancière apresenta sua perspectiva sobre o mesmo tema em "A Imagem Intolerável". Rancière inicia seu texto perguntando: "o que torna uma imagem intolerável? [...] Será tolerável criar tais imagens e propô-las à visão alheia?" (RANCIÈRE, 2014, p. 83). O próprio autor, no entanto, aponta para a armadilha da crítica ao espetáculo que culpa o excesso de imagens pela letargia em que se encontra o espectador contemporâneo:

Precisamos questionar essas identificações do uso das imagens com a idolatria, a ignorância ou a passividade, se quisermos lançar um novo olhar sobre o que essas imagens são, o que fazem e os efeitos que produzem [...]. É preciso pôr em causa a opinião corrente segundo a qual esse sistema [oficial de informação] nos submerge em uma vaga de imagens em geral - e imagens de horror em particular - tornandonos assim insensíveis à realidade banalizada desses horrores". (RANCIÈRE, 2014, p. 93-94).

A despeito de sua intenção crítica, a tese corrente de que o mal das imagens está em sua quantidade corrobora o funcionamento do sistema de informação oficial, ocultando o fato de que os meios de comunicação dominantes não nos

\footnotetext{
$\overline{8}$ No original: "For the photography of the atrocity, people want the weight of witnessing without the taint of artistry, which is equated with insincerity or mere contrivance" (SONTAG, 2003, p. 26).

${ }^{9}$ No original: "Perhaps the only people with the right to look at images of suffering of this extreme order are those who could do something to alleviate it [...] or those who could learn from it” (SONTAG, 2003, p. 42).
} 
mostram, efetivamente, uma quantidade inapreensível de imagens de violência, mas, ao contrário, "reduzem seu número, tomam bastante cuidado para selecionálas e ordená-las" (RANCIĖRE, 2014, p. 94). Tal paradoxo, mesmo que passe muitas vezes despercebido, talvez explique a necessidade de artistas e fotógrafos se voltarem frequentemente para esse tipo de imagem, com o intuito, como no caso da Garapa, de problematizá-las e recolocá-las em debate. Para Rancière,

se o horror está banalizado, não é porque vemos imagens demais. Não vemos corpos demais a sofrerem na tela. Mas vemos corpos demais sem nome, corpos demais incapazes de nos devolver o olhar que lhes dirigimos, corpos que são objeto de palavra sem terem a palavra (2014, p. 94).

"Postais para Charles Lynch" é uma coleção de imagens da brutalidade contemporânea retiradas de frames de vídeos que circulam clandestinamente pela internet, que foram rastreados e armazenados ao longo de meses pelo coletivo. Há um delicado limite ético implicado no trabalho com esse tipo de imagem, que envolve até mesmo a decisão de olhar ou não para elas. Sabe-se que, na maioria das vezes, os vídeos são produzidos por pessoas que presenciaram as agressões e que, na melhor das hipóteses, em vez de agir para interromper as ações, optaram por registrá-las e, em algum momento, decidiram divulgá-las, alimentando um círculo voyeurístico que estimula a reprodução da violência.

Ao mesmo tempo, esse tipo de imagem encontra-se há séculos em circulação, afetando o modo como percebemos e interpretamos o mundo. Ignorá-las pode constituir, também, uma forma de ignorar o sofrimento real infringido àqueles que nelas estão representados (SONTAG, 2003). Para Rancière, a possibilidade de tratar do que é visivelmente intolerável é uma questão de dispositivo de visibilidade, um sistema cuja visibilidade considera-se compartilhada por todos e que "cria certo senso de realidade, certo senso comum" (2014, p. 99).

Mas qual o sentido que as interferências plásticas provocadas por erros programados conferem aos trechos de vídeos apropriados pela Garapa? Em primeiro lugar, elas parecem expor a fragilidade das imagens digitais, cujos arquivos podem ser corrompidos não apenas intencionalmente, como no caso de "Postais para Charles Lynch", mas durante sua própria migração de dispositivo para dispositivo e suas sucessivas gravações e visualizações. Em segundo lugar, mas de forma igualmente importante, elas conferem às imagens desses vídeos clandestinos o estatuto de arte e, com ele, o direito de circular em canais oficiais. Por meio dessa intervenção estética e desse decorrente processo de institucionalização, essas imagens se tornam eticamente toleráveis, podendo ser apresentadas em exposições, palestras e textos a um público mais amplo, que normalmente desviaria o olhar diante desse tipo de imagem. Como deixar-se afetar e como reagir a elas, a partir disso, fica a cargo do espectador. 


\section{REFERÊNCIAS}

ALLEN, James. Without Sanctuary: Lynching Photography in America. Santa Fé: Twin Palms Publishers, 2000.

FONTCUBERTA, Joan. "Por um manifesto pós-fotográfico". Studium, Campinas, n.36, jul. 2014. Disponível em: < http://www.studium.iar.unicamp.br/36/7/>. Acesso: 15 ago. 2017.

GARAPA. Postais para Charles Lynch (notas de um percurso sobre a barbárie). São Paulo: Garapa, 2015. Disponível em: <https://medium.com/mal-secreto/notas-de-um-percurso-pela-barb\%C3\%A1rie5dfb35cc3929\#.u1xr4uuhs>. Acesso: 30 jul. 2017.

OLIVEIRA, Pâmela. Jovem preso a poste por 'justiceiros' perambula há dois anos pelas ruas do Rio. VEJA, Rio de Janeiro, 5 fev. 2014. Disponível em: < https://veja.abril.com.br/brasil/jovem-preso-a-poste-porjusticeiros-perambula-ha-dois-anos-pelas-ruas-do-rio/> . Acesso em: 12 set. 2017.

https://doi.org/10.17771/pucrio.acad.11775

RANCIĖRE, Jacques. O espectador emancipado. São Paulo: Editora WMF Martins

Fontes, 2012.

SONTAG, Susan. Regarding the pain of others. Nova York: Picador, 2003.

STEYERL, Hito. "In defense of the poor image". In: The wretched of the screen. Berlin: Stenberg Press, 2012, p. 31-45.

Recebido em 09/12/2018 - Aprovado em 05/04/2019

Como citar:

Schenkel, C. M. (2019) Violentar o Corpo da Imagem: uma estratégia para representar e resistir à barbárie. OuvirOUver, 15(1), 158-170. https://doi.org/10.14393/OUV24-v15n1a2019-11

(c) (7) (5) A revista ouvirOUver está licenciada com uma Licença Creative EY Commons Atribuição-NãoComercial 4.0 Internacional. 